\title{
Characterization of Non-proprietary UHPC for Use in Rehabilitation/Strengthening Applications
}

\author{
Ana Mafalda Matos ${ }^{1(\bowtie)}$, Sandra Nunes ${ }^{1}$, Carla Costa $^{2}$, \\ and José L. Barroso-Aguiar ${ }^{3}$ \\ ${ }^{1}$ CONSTRUCT-LABEST, Faculty of Engineering, \\ University of Porto, Porto, Portugal \\ ana.matos@fe.up.pt \\ 2 High Institute of Engineering of Lisbon (ISEL), \\ Lisbon Polytechnic Institute, Lisbon, Portugal \\ 3 School of Engineering, University of Minho, Guimarães, Portugal
}

\begin{abstract}
UHPFRC has become one of the most promising cement-based materials for the next generation of infrastructures because of its good workability, outstanding mechanical properties, and excellent durability. A promising field of application is the rehabilitation and/or strengthening of existing reinforced concrete structures, in which a new layer of UHPFRC replaces the deteriorated concrete (cracked, carbonated, chloride attack, etc.). The combination of the UHPFRC as protective layer, which can be reinforced, provides a simple and efficient way of increasing the durability (extending the service life), the stiffness and structural resistance capacity while keeping compact cross sections. A study was carried out to test a non-proprietary UHPC mix containing equilibrium catalyst to determine whether this new mix is a viable option for rehabilitation/strengthening applications. Several mechanical properties and durability were assessed, such as early age E-modulus development and autogenous shrinkage, compressive strength evolution in time, uniaxial tensile strength, water absorption by capillarity, chloride ion penetration, alkali-silica reactivity and sulphates attack resistance. Test results show that new UHPC developed present equivalent performance to other UHPCs cured under normal curing conditions.
\end{abstract}

Keywords: UHPFRC - Early age E-modulus - Autogenous shrinkage · Uniaxial tensile strength $\cdot$ Durability

\section{Introduction}

Ultra-High Performance Fibre Reinforced Composites (UHPFRC) refer to the family of composite materials containing a large amount of short steel fibres evenly embedded in an ultra-compact cementitious matrix (hereafter, UHPC) with a high content of the binding phase including cement and supplementary cementitious materials (SCMs) and a very low water to binder ratio $(\mathrm{w} / \mathrm{b}<0.2)$. The main principles for UHPFRC design are reduction in porosity, improvement in microstructure, enhancement in homogeneity 
and increase in toughness. The raw materials, the curing regimes and the fibres content are the main factors that control the mechanical properties and durability of UHPFRC [1]. The raw materials of UHPFRC include a cementitious component (typically, cement and silica fume), fine inert fillers, quartz sand $\left(\mathrm{d}_{\max }<1 \mathrm{~mm}\right)$, superplasticizer, and fibres. It has been shown that granulated blast furnace slag, fly ash, metakaolin, limestone powder, rice husk ash can be used to replace silica fume in UHPC [2]. Fibres used in UHPFRC are often high-strength micro steel fibres with length of $13 \mathrm{~mm}$ and diameter of $0.2 \mathrm{~mm}$. Considering the high cost and complexity of curing processes, such as heat curing and autoclave curing, use of conventional materials and common technology, such as conventional casting and room temperature curing has been preferred by several authors in order to facilitate the production and applications of UHPFRC.

Most current applications of UHPFRC in new structures are accomplished by factory pre-fabrication and on-site assembling, such as very slender and lightweight elements for pedestrian footbridges and highway bridges, and architecturally and aesthetically appealing structures. On-site fabrication of UHPFRC is mainly limited to rehabilitation and strengthening purposes. The main advantage of UHPFRC in this context is that it can play a double function (water tightness and strengthening) while enabling short-time interventions. Although UHPFRC is being utilized in several applications around the world, it still faces some challenges for wider implementation. A PhD research programme is currently underway at the Faculty of Engineering, Porto University, Portugal (FEUP), aiming to address some of those challenges, namely:

1. To develop a rational and accurate method for the mixture design and optimization of UHPC

2. To use locally available supplementary cementitious materials (including industrial residues) for partial replacement of cement and silica fume, in order to reduce the materials cost of UHPC, while achieving a minimum compressive strength of $150 \mathrm{MPa}$ after normal curing regime

3. To mitigate autogenous shrinkage of UHPC to minimize early ages cracking risk (which might impair its durability), particularly when the deformations are restrained as is the case in rehabilitation/strengthening applications.

\section{Experimental Programme}

\subsection{Materials Characterization and Mixture Proportions}

The cement used in this study is ordinary Portland cement (CEM I 42.5 R), in accordance with the standard EN 197-1. Silica fume $\left(\mathrm{SiO}_{2}\right.$ content $\left.>90 \mathrm{v} \%\right)$ with a specific surface area of $19632 \mathrm{~m}^{2} / \mathrm{kg}$ (BET method) and limestone filler $\left(98 \mathrm{v} \% \mathrm{CaCO}_{3}\right)$ having a specific surface of $550 \mathrm{~m}^{2} / \mathrm{kg}$ (Blaine method) were used to increase the compactness of the matrix. The aggregate phase consisted of a mixture of siliceous natural sand (1 mm maximum size) and a spent equilibrium catalyst, generated by Sines Refinery, Portugal (ECat). Chemically, the ECat is essentially an aluminosilicate which main active phase is Y-zeolite, a crystalline aluminosilicate with a structure 
consisting of tunnels and cages that leads to a high (internal and external) surface specific area. Due to its aluminosilicate chemical composition, ECat has a potential pozzolanic activity; hence, is likely to be used as a cement-based material additive. Results of modified Chapelle test method (according to French standard NF P18-513) reveal that $1540 \mathrm{mg}$ and $1577 \mathrm{mg}$ of $\mathrm{Ca}(\mathrm{OH})_{2}$ are consumed per $\mathrm{g}$ of ECat and per $\mathrm{g}$ of SF, respectively, suggesting that both materials have high pozzolanic activity. Moreover, the high specific surface of the ECat $\left(150070 \mathrm{~m}^{2} / \mathrm{Kg}\right.$, BET method) with water affinity promotes significant water absorption (about $30 \%$, by mass). Thus, this residue is used in the current work as an internal curing agent in UHPFRC. A polycarboxylatebased superplasticizer (SP) was also used, with a solid content of $40 \%$. High strength short steel fibres with $0.2 \mathrm{~mm}$ in diameter and $13 \mathrm{~mm}$ in length $\left(l_{f} / d_{f}=65\right)$ were used as reinforcement. The tensile strength and modulus of elasticity of the fibres are $2750 \mathrm{MPa}$ and $200 \mathrm{GPa}$, respectively.

The design of experiments (DOE) approach (combining statistical and mathematical methods of experiment design, regression analysis and optimisation techniques) was employed to reduce the effort necessary to achieve the target engineering properties of the UHPC, namely, self-compatibility, low autogenous shrinkage, improved durability and high mechanical performance, as described in [3]. Figure 1(a) shows the volumetric composition of the optimized UHPC mixture which is going to be characterized in the current study. Steel fibres were added to UHPC in volume fraction of $3 \%$ to manufacture a UHPFRC mixture, by replacing an equivalent volume of aggregates.

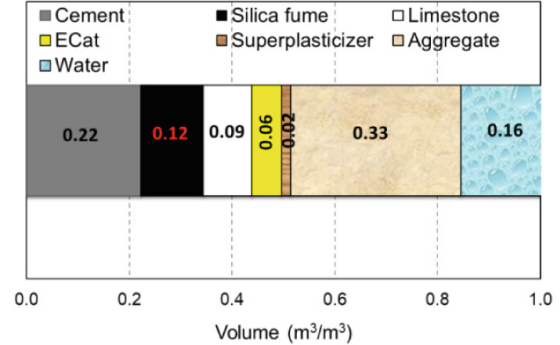

a)

\begin{tabular}{c|l|c}
\hline Step & \multicolumn{1}{|c|}{ Task } & Duration \\
\hline 1$)$ & add ECat + water1 and mix & $5 \mathrm{~min}$ \\
$2)$ & add sand + powder materials and mix & $2.5 \mathrm{~min}+*+2.5 \mathrm{~min}$ \\
$3)$ & add water2 +75\% superpl. and mix & $2.5 \mathrm{~min}$ \\
$4)$ & add 25\% superpl. and mix & $3.5 \mathrm{~min}$ \\
\hline
\end{tabular}

water $1=(80 \%$ mixing water + water for Ecat absorption $)$;water $2=20 \%$ mixing water; $(*)$ stoppage to scrape material adhering to the mixing bowl; mixing at low speed $\left(140 \pm 5\right.$ rotations $\left.\cdot \mathrm{min}^{-1}\right)$

b)

Fig. 1. (a) Mixture proportions of non-proprietary UHPC tested, in terms of volume; (b) Mixing sequence.

\subsection{Test Methods}

The UHPC mixture was produced according to the mixing procedure described in Fig. 1(b), using a mixer in accordance with the standard EN 196-1. The UHPFRC mixture preparation followed the same mixing procedure, except for the fibres incorporation during $2 \mathrm{~min}$ before the end of the mixing process.

Immediately after mixing, the slump-flow diameter was measured using a truncated cone $\left(\phi_{\text {upper }}=70 \mathrm{~mm} ; \phi_{\text {lower }}=100 \mathrm{~mm} ; h=60 \mathrm{~mm}\right)$, without any compaction 
energy. The autogenous shrinkage of UHPC mixture was measured based on the ASTM C1698, using sealed corrugated tubes of $440 \mathrm{~mm}$ length and $28.5 \mathrm{~mm}$ average diameter. After filling the tubes, each specimen was measured, weighted and kept inside a chamber with controlled temperature $\left(23{ }^{\circ} \mathrm{C} \pm 1{ }^{\circ} \mathrm{C}\right)$. Shrinkage deformations were recorded continuously using linear variable differential transformers (LVDTs) and a data Taker DT500 acquisition system, up to 7 days. The final setting time, determined according to the standard EN 196-3, was considered as "time-zero" for the autogenous shrinkage evaluation. The Elasticity Modulus Measurement based on Ambient Response Method (EMM-ARM) [4] was used to continuously monitor the E-modulus evolution of UHPC since casting. The EMM-ARM is based on the identification of the resonant frequency of the testing mould (plastic hollow cylinder in simply supported conditions, filled with the sample to be tested immediately after mixing), which evolves along time due to the progress of hydration reactions. By monitoring the accelerations of the composite beam at mid-span, it is possible to perform the modal identification and to evaluate the first flexural resonance frequency of the beam. The E-modulus of the UHPC mixture could be inferred with basis on the dynamic equations of motion of the testing system [4].

Cubic specimens $(50 \mathrm{~mm})$ were produced to assess the compressive strength evolution up to 90 days. Specimens were kept under water in a chamber under controlled temperature $\left(20{ }^{\circ} \mathrm{C} \pm 2{ }^{\circ} \mathrm{C}\right)$ until testing age. The uniaxial tensile test (UTT) was carried out using six dog bone-shaped UHPFRC specimens, with a tested section length of $92 \mathrm{~mm}$ and cross section of $30 \mathrm{~mm} \times 40 \mathrm{~mm}$, after 28 curing days in a controlled environment room (temperature $=20{ }^{\circ} \mathrm{C} \pm 2{ }^{\circ} \mathrm{C}$ and $\mathrm{HR}>95 \%$ ). Specimens were tested at a constant displacement rate of $0.003 \mathrm{~mm} / \mathrm{s}$. The elongation of the specimens was measured using four LVDT's system coupled along the tested section length of the specimen.

Concerning the durability, several tests were carried out on sound UHPC specimens to assess its resistance to the penetration of aggressive agents, as well as, the proneness to expansive reactions. The corresponding experimental plan is detailed in Table 1. Accelerated carbonation tests are also underway, but no carbonation front was detected in the specimens until the current date ( 9 months).

\section{Results and Discussion}

\subsection{Flowability and Early Ages Properties}

Both UHPC and UHPFRC mixtures exhibited high viscosity and good deformability with final spread diameters of $312.0 \mathrm{~mm}$ and $282.5 \mathrm{~mm}$, respectively. Taking in consideration, the low water to binder ratio and high binder content in UHPC one would anticipate a large early autogenous shrinkage. In fact, the most typical UHPC mixtures (cement + large amounts of SF) reach values as high as $1119 \mu \mathrm{m} / \mathrm{m}$ at 7 days ("Previous UHPC" in Fig. 2(a)) [5]. Figure 2(a) shows that the UHPC mixture under study ("New UHPC") exhibits significantly less autogenous shrinkage (about $700 \mu \mathrm{m} / \mathrm{mm}$ at 7 days) attributed to the significant amount of water absorbed by ECat. The amount of extra water absorbed by ECat in the current mixture was $46.6 \mathrm{~L} / \mathrm{m}^{3}$, which is similar to 
the water absorption capacity of superabsorbent polymers or lightweight aggregates often used for internal curing in UHPC [3]. The temperature increase inside the thin autogenous shrinkage test samples was very small $\left(1{ }^{\circ} \mathrm{C}\right.$ to $\left.2{ }^{\circ} \mathrm{C}\right)$, thus no temperature correction was included.

Young Modulus evolution curve presented in Fig. 2(b) shows an initial dormant period, with duration close to $3 \mathrm{~h}$, after which a strong evolution of the E-modulus was observed up to about $9 \mathrm{~h}$, after the end of mixing. After this stage, a dramatic reduction in the slope of Young Modulus evolution occurs, and a Young modulus of about 36 GPa was achieved after 7 days. In the same figure, the E-modulus evolution of a conventional mortar $(\mathrm{w} / \mathrm{c}=0.40)$ is also plotted, showing a dormant period significantly longer and a rate of E-modulus evolution clearly slower. The addition of fibres in UHPFRC did not significantly influence its elastic modulus, but further reduces the autogenous shrinkage due to the locally shrinkage-restraining effect of fibres [3]. Both autogenous shrinkage and Young's modulus evolution will influence the development of self-induced stresses in the presence of external restraint, which will determine the risk of cracking at early ages.

Table 1. Durability testing plan carried out on sound UHPC specimens.

\begin{tabular}{l|l|l|l|l}
\hline $\begin{array}{l}\text { Durability } \\
\text { indicator }\end{array}$ & $\begin{array}{l}\text { Test standard/ } \\
\text { technique }\end{array}$ & Testing age & $\begin{array}{l}\text { Number of } \\
\text { specimens }\end{array}$ & Specimens geometry \\
\hline $\begin{array}{l}\text { Total } \\
\text { porosity and } \\
\text { pore size } \\
\text { distribution }\end{array}$ & $\begin{array}{l}\text { MIP } \\
\text { Poremaster-60 } \\
\text { equipment }\end{array}$ & 28,90 days & 2 & $\begin{array}{l}\text { Cylinder } \\
\mathrm{h}=30 \mathrm{~mm}, \\
\emptyset=9 \mathrm{~mm}\end{array}$ \\
\hline $\begin{array}{l}\text { Water } \\
\text { permeable } \\
\text { porosity }\end{array}$ & $\begin{array}{l}\text { Vacuum } \\
\text { saturation } \\
\text { approach }\end{array}$ & 28 days & 6 & $\begin{array}{l}\text { Cylinders } \\
\mathrm{h}=30 \mathrm{~mm}, \\
\varnothing=50 \mathrm{~mm}\end{array}$ \\
\hline $\begin{array}{l}\text { Water } \\
\text { absorption by } \\
\text { capillarity }\end{array}$ & $\begin{array}{l}\text { RILEM TC } \\
116-P C D\end{array}$ & $\begin{array}{l}28 \text { days }(+14 \\
\text { days at } 40{ }^{\circ} \mathrm{C}, \\
\text { until constant } \\
\text { mass })\end{array}$ & 5 & $\begin{array}{l}\text { Prisms } \\
40 \times 40 \times 45 \mathrm{~mm}^{3}\end{array}$ \\
\hline $\begin{array}{l}\text { Resistance to } \\
\text { chlorides } \\
\text { penetration }\end{array}$ & NT Build 492 & 28 days & 6 & $\begin{array}{l}\text { Cylinders } \\
\mathrm{h}=50 \mathrm{~mm}, \\
\varnothing=100 \mathrm{~mm}\end{array}$ \\
\hline $\begin{array}{l}\text { Resistance to } \\
\text { sulphate } \\
\text { attack }\end{array}$ & $\begin{array}{l}\text { Portuguese } \\
\text { specification } \\
\text { E-462 }\end{array}$ & - & $\begin{array}{l}\text { Prisms } \\
20 \times 20 \times 160 \mathrm{~mm}^{3}\end{array}$ \\
\hline $\begin{array}{l}\text { Risk of } \\
\text { alkali-silica } \\
\text { reaction }\end{array}$ & $\begin{array}{l}\text { ASTM C } \\
1260\end{array}$ & 28 days* & 3 & $\begin{array}{l}\text { Prisms } \\
25 \times 25 \times 285 \mathrm{~mm}^{3}\end{array}$ \\
\hline
\end{tabular}

(*) Specimens were subjected to heat curing according to the procedure proposed in ASTM C1260. 


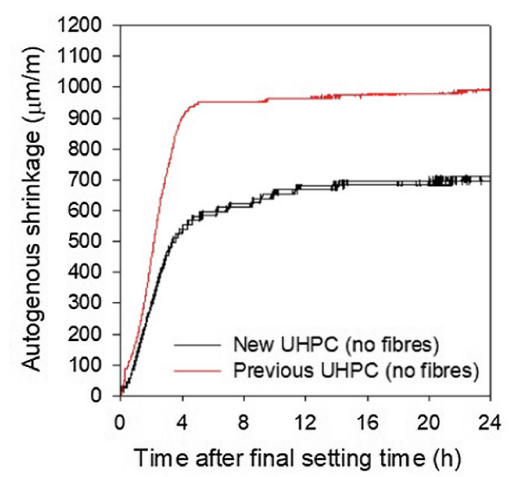

a)

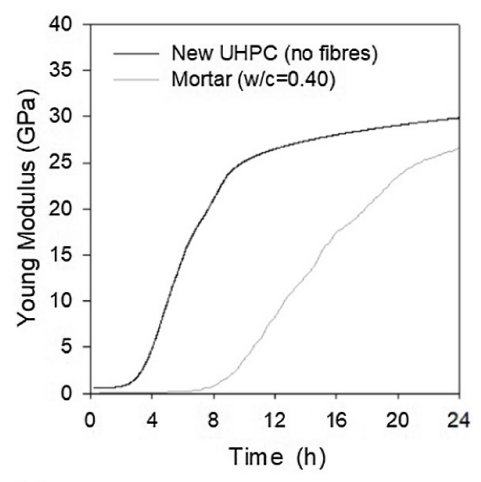

b)

Fig. 2. (a) Autogenous shrinkage and (b) E-modulus evolution of UHPC up to $24 \mathrm{~h}$.

\subsection{Mechanical Performance}

Figure 3(a) shows the increase in compressive strength of the UHPFRC mixture under study, up to 90 days. Compressive strengths of $147 \mathrm{MPa}$ and $156 \mathrm{MPa}$ were achieved, respectively, after 28 days and 90 days, without special curing conditions. Concerning the tensile behaviour, Fig. 3(b) shows that the UHPFRC exhibited a uniaxial tensile peak stress and a peak strain ranging from $11 \mathrm{MPa}$ to $15 \mathrm{MPa}$ and $0.27 \%$ to $0.47 \%$, respectively, at 28 days, which compare well with results reported in the literature for UHPFRCs with other cementitious matrixes and same fibre content [6]. A significant tensile-hardening branch was observed in most specimens, particularly, for the specimens with more favourable fibres orientation.

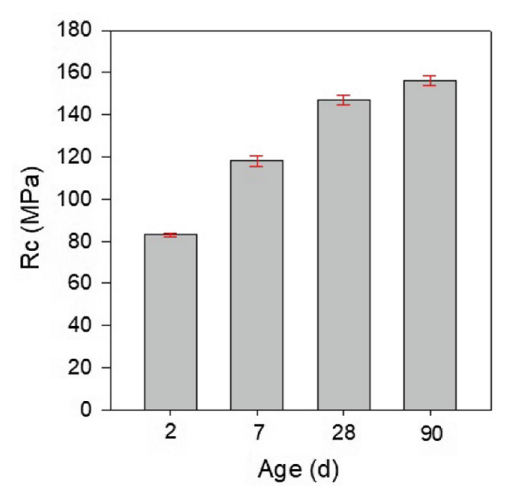

a)

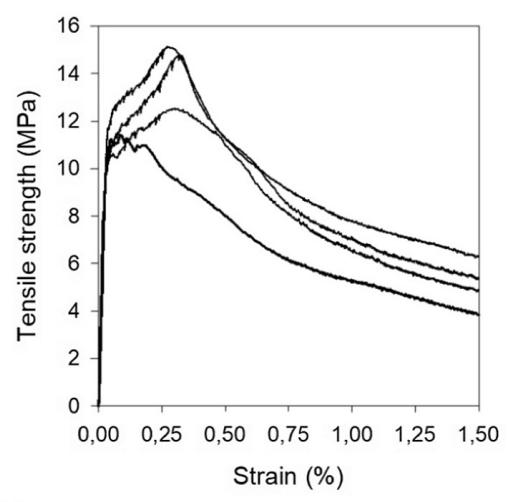

b)

Fig. 3. (a) Compressive strength of the UHPFRC mixture at different ages and (b) UTT curves at 28 days of replicate UHPFRC specimens. 


\subsection{Durability Indicators}

Whereas typical UHPFRCs (incorporating cement + large amounts of SF) are cured thermally, the UHPC under study was not and, therefore, it was expected to be more porous. The average water permeable porosity of UHPC was $14 \%$ and total porosity assessed by MIP was $4.8 \%$, after 28 days of wet curing. Figure 4(a) shows only a small percentage of the total porosity corresponds to capillary pores $(0.01 \mu \mathrm{m}-1 \mu \mathrm{m})$. A further reduction in pore sizes and capillarity porosity was observed after 90 days of curing, which can be attributed to the pozzolanic effect of SF and ECat. The average water sorptivity coefficient of UHPC was $0.014 \mathrm{mg} /\left(\mathrm{mm}^{2} \mathrm{~min}^{-1 / 2}\right)$, which is approximately 6 times lower compared to that of good quality conventional concrete $(w / c=0.40)$. Likewise, UHPC showed low chloride diffusion coefficient of $1.99 \times 10^{-12} \mathrm{~m}^{2} / \mathrm{s}$, on average. Figure 4(b) shows the expansion of the small UHPC prisms during ASR testing. The average expansion value measured of $0.0180 \%$, after 14 days of testing, is much lower than the limit of $0.10 \%$ as prescribed in the ASTM C1260-94 standard. Thus, it seems there is no risk of physical damage due to the deleterious expansion associated to the ASR occurrence. The UHPC prisms of $20 \mathrm{~mm} \times 20 \mathrm{~mm} \times 160 \mathrm{~mm}$ were immersed in a sodium sulphate solution $\left(\mathrm{Na}_{2} \mathrm{SO}_{4}, 16 \mathrm{~g} \mathrm{SO}_{4}{ }^{2-}\right.$ per litre $)$ and the length variation was regularly measured. The results indicate no significant expansion $(0.002 \%)$ or visual deterioration, even after 26 weeks of immersion.

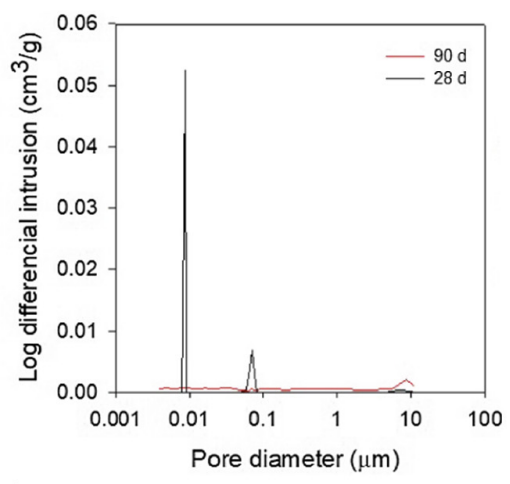

a)

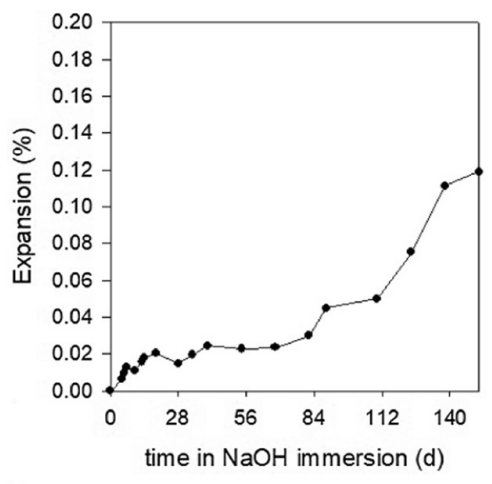

b)

Fig. 4. (a) MIP curves of the UHPC after 28 and 90 days of water curing at $20{ }^{\circ} \mathrm{C}$; (b) Change in the specimens' length due to the occurrence of ASR in the UHPC.

\section{Conclusions}

The current work investigated the performance of a non-proprietary UHPC mixture based on rational selection and proportioning of raw materials and using normal curing conditions. The incorporation of ECat, and the corresponding extra water that the ECat is able to absorb, lead to a significant reduction of the autogenous shrinkage of UHPC, while maintaining excellent workability in the fresh state. The high strength and 
durability of typical UHPFRCs are highly dependent on thermal treatment. Despite being cured at $20{ }^{\circ} \mathrm{C}$ in a wet chamber, the investigated UHPFRC achieved a compressive strength of 147 and $156 \mathrm{MPa}$ after 28 and 90 days, respectively; and exhibited a tensile strain-hardening behaviour with multiple micro-cracking formation. MIP testing and water sorptivity coefficient results showed that the primary reason for UHPC enhanced durability is its highly dense matrix phase, caused by a very low water to binder ratio and by the presence of very active pozzolans (silica fume and ECat) that gave rise to a very low capillary porosity. Accelerated testing also revealed that the studied UHPC presents a very good performance in terms of resistance to expansive reactions, namely, alkali-silica and external sulphates attack.

Acknowledgements. This work was financially supported by: UID/ECI/04708/2019- CONSTRUCT funded by national funds through the FCT/MCTES (PIDDAC); the project POCI-010145-FEDER-031777- UHPGRADE funded by FEDER funds through COMPETE2020 - Programa Operacional Competitividade e Internacionalização (POCI) and by national funds (PIDDAC) through FCT/MCTES; and by FCT PhD scholarship PD/BD/113636/2015-Doctoral Program EcoCoRe. Collaboration and materials supply by Sines Refinery/Galp Energia, Secil, Omya Comital, Sika, Bekaert and Euromodal is gratefully acknowledged.

\section{References}

1. Wang D, Shi C, Wu Z, Xiao J, Huang Z, Fang Z (2015) A review on ultra high performance concrete: part II. Hydration, microstructure and properties. Constr Build Mater 96:368-377

2. Shi C, Wu Z, Xiao J, Wang D, Huang Z, Fang Z (2015) A review on ultra high performance concrete: part I. Raw materials and mixture design. Constr Build Mater 101:741-751

3. Matos MA, Nunes S, Costa C, Aguiar José Luís B (2019) Spent equilibrium catalyst as internal curing agent in UHPFRC. Cem Concr Compos 104:103362

4. Granja J, Azenha M (2017) Towards a robust and versatile method for monitoring E-modulus of concrete since casting: enhancements and extensions of EMM-ARM. Strain 53:e12232

5. Mafalda Matos A, Nunes S, Costa C (2016) Mitigation of early age shrinkage of UHPFRC by using spent equilibrium catalyst. In: International RILEM conference materials, systems and structures in civil engineering 2016 segment on service life of cement-based materials and structures

6. Abrishambaf A, Pimentel M, Nunes S (2017) Influence of fibre orientation on the tensile behaviour of ultra-high performance fibre reinforced cementitious composites. Cem Concr Res 97:28-40 